\title{
Differences in Mating Propensity Between Immature Female Color Morphs in the Damselfly Ischnura elegans (Insecta: Odonata)
}

\author{
Martijn Hammers • Rosa Ana Sánchez-Guillén • \\ Hans Van Gossum
}

Revised: 26 November 2008 / Accepted: 20 February 2009 /

Published online: 11 March 2009

(C) The Author(s) 2009. This article is published with open access at Springerlink.com

\begin{abstract}
Female-limited color polymorphisms occur in a variety of animal taxa where excessive male sexual harassment may explain the coexistence of multiple female color morphs. In the color polymorphic damselfly Ischnura elegans, mature and immature female color morphs coexist at the mating site where males are in search for suitable mating partners. Here, we study male preference and female mating propensity for the two immature female morphs. As would be expected, compared to mature morphs, both immature female morphs mate much less. Within immature females, one morph consistently mates more frequently compared to the other morph, a pattern that is similar for the ontogenetically corresponding mature female morphs. Preference experiments with the two differently colored immature female morphs, however, did not indicate male mate preference for either morph. Low mating frequencies of immature females at natural sites in combination with relatively high attractiveness of immature models in terms of male preference indicate that female behavior influences female mating success.
\end{abstract}

Keywords Color polymorphism $\cdot$ male preference $\cdot$ mating success $\cdot$ Odonata . Ischnura elegans

\footnotetext{
M. Hammers

Animal Ecology Group, Centre for Ecological and Evolutionary Studies, University of Groningen, P.O. Box 14, 9750 AA Haren, The Netherlands
}

R. A. Sánchez-Guillén

Departamento de Ecoloxía e Bioloxía Animal, Universidade de Vigo, EUET Forestal, Campus Universitario, 36005 Pontevedra, Spain

H. Van Gossum ( $\square)$

Evolutionary Ecology Group, University of Antwerp, Groenenborgerlaan 171, 2020 Antwerp,

Belgium

e-mail: hans.vangossum@ua.ac.be 


\section{Introduction}

For species that show sexual conflict over fertilizations, reproductive success in males typically is optimized through maximization of the mating rate. Females, in contrast, only tend to require mating a few times to produce their optimal number of viable eggs (e.g. Arnqvist and Nilsson 2000). Consequently, females are expected to receive more male sexual attention than desired, which may interfere with female time and energy budgets and may even lead to injuries (e.g. Crudgington and Siva-Jothy 2000). To avoid costs associated with excessive male sexual harassment, females will be selected to develop counter-adaptations. These may include avoiding encounters with males (e.g. Krupa et al. 1990) or forming associations with single males (e.g. Clutton-Brock et al. 1992; Rowe et al. 1994). Another adaptation in response to costly superfluous male mating attempts may be female-limited polymorphism, where one female morph may avoid recognition by males through resembling the male's phenotype (Robertson 1985; Cook et al. 1994). Femalelimited color polymorphism is observed in a variety of vertebrate and invertebrate taxa, including birds (Galeotti et al. 2003), fish (Turner et al. 2001), lizards (Vercken et al. 2007) and insects (Nielsen and Watt 2000). Where it occurs sexual selection has often been indicated as a driving force for coexistence of multiple female morphs in natural populations (Gross 1996; Gray and Mckinnon 2007).

In the case of odonates, female-limited polymorphism is common (Fincke et al. 2005) and female morphs differ in body coloration and sometimes in behavior (e.g. Sirot et al. 2003; Fincke et al. 2005). Odonates have extraordinarily developed color vision (Armett-Kibel and Meinertzhagen 1983; Corbet 1999; Briscoe and Chittka 2001), which makes coloration one of the most important visual cues for males in mate recognition (Corbet 1999). Males may face little challenge in recognizing females based on body coloration when only one female type is present, but could become distracted when faced with multiple female color morphs (Fincke 2004). Interestingly, one of the female morphs in damselflies is similar in body color to the conspecific male (androchrome), while the other(s) is (are) not (gynochrome). Similar to predators forming a search image for the most common prey type (e.g. Murdoch 1969), frequency-dependent mate selection may act on female morphs, with female color morphs receiving different amounts of male sexual harassment (e.g. Miller and Fincke 1999; Van Gossum et al. 1999; Van Gossum et al. 2001a, b). Alternatively, or in addition, mate-searching males may be challenged when part of their potential female partners resemble the conspecific male's phenotype and behavior. Such a female morph is considered a functional male-mimic that gains an advantage over the other female morphs as it receives less male attention (e.g. Robertson 1985; Sherratt 2001). Most studies to date mainly focused on male mate preference, while male and female mating success not only depends on male mate preference, but also on female willingness to mate.

Indeed, due to the mating morphology of damselflies, males can only achieve copulation if females cooperate (see Fincke et al. 1997 for review; but see Cordero and Andrés 2002). Males will attempt to clasp a female at her pronotum using their anal appendages to reach tandem formation (e.g. Miller 1987). After this, females have the opportunity to reject male mating attempts and not to proceed from tandem to copula, thus the ability to prevent sperm transfer. Males may try to form tandems 
with female morphs in a frequency-dependent manner (Miller and Fincke 1999; Van Gossum et al. 1999; Van Gossum et al. 2001a, b) or depending on whether the female resembles the conspecific male (i.e. mimicry; e.g. Cordero et al. 1998; Cordero Rivera and Sánchez-Guillén 2007). However, the female's willingness to accept or reject male mating attempts will determine whether the male is successful (e.g. Van Gossum et al. 2001a; Sirot et al. 2003). Interestingly, mature female morphs of Ischnura elegans have been shown to differ in resistance and tolerance to male mating attempts (Gosden and Svensson 2007). Females may resist male mating attempts for several reasons, for instance when they do not carry mature eggs while immature or after oviposition when new eggs have to mature. Further, females may still have sufficient good quality sperm stored from previous matings for egg fertilization.

In most damselfly species, female morphs develop their adult coloration only a few days after metamorphosis from aquatic larvae into flying insect. Mostly, these immature individuals spend their maturation period away from the reproductive site (e.g. Miller 1987). However, in some species, for example I. elegans, immature and mature females do coexist at the reproductive site (Parr 1973; Fincke 1987; Hinnekint 1987). Also, in I. elegans, female body coloration changes with age with clearly differently colored immature and mature female morphs (e.g. Cordero et al. 1998; Sánchez-Guillén et al. 2005; Fig. 1). Mark-recapture work with I. ramburi indicated that $23 \%$ of observed mating females were immature (Sirot et al. 2003). It is possible that differences in female coloration facilitate male mating decisions and allows them to discriminate between immature and mature females. In support, male mate preference experiments in I. graellsii and I. elegans have indicated that males do not mate immature and mature females at random (Cordero 1989; Gorb 1999; Van Gossum et al. 2001c). Furthermore, immature females also differ in body coloration, and in I. graellsii these morphs differ in male attraction (Cordero 1989). Sirot et al. (2003) and Fincke et al. (2005) stressed that for species where ontogenetic

Age-related color changes

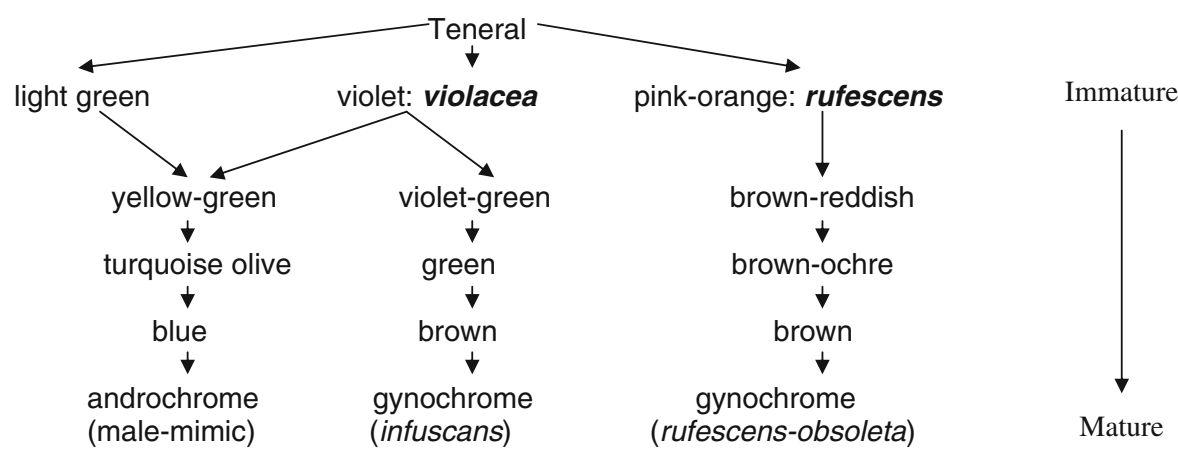

Fig. 1 The relationship between color polymorphism and age-related color changes in females of Ischnura elegans (see Sánchez-Guillén et al., 2005). Age-related changes in female morph body coloration are presented on a chronological scale, starting with just metamorphosed individuals that are called teneral. For our experiments and observations we only considered violacea and rufescens as immature females. 
color changes occur, considering mating frequencies of males with immature females might be needed to fully appreciate mating frequencies of mature females.

Here we studied I. elegans to determine how frequent immature female morphs compare to mature morphs. We estimated population frequencies of female morphs and used these frequencies for predicting female mating frequencies, while further comparing these estimated mating frequencies to observed mating frequencies ( $c f$. Cordero Rivera and Sánchez-Guillén 2007; Hammers and Van Gossum 2008). In addition, we conducted experimental presentation trials to evaluate whether males are differently attracted to either immature female morph.

\section{Materials and Methods}

\section{Study Species}

In the damselfly I. elegans (body size of about $3 \mathrm{~cm}$; Askew 2004) mature female occur as one of three color morphs (Fig. 1): androchrome (male-mimic) and two gynochromes (infuscans and rufescens-obsoleta). Androchrome females closely resemble conspecific males in body coloration and patterning, whereas gynochromes do not. The expression of this color polymorphism is consistent with the hypothesis that it is controlled by three alleles on a single locus with sex-limited expression where the androchrome morph is dominant (Sánchez-Guillén et al. 2005). For immature females, two color morphs are distinguished: rufescens that is the immature stage of rufescens-obsoleta and violacea that transforms into either an androchrome or an infuscans female (see Cordero et al. 1998). While it cannot always be inferred to which mature female morph the violacea form will develop, it has been shown that a black mark on the dorsum of the eighth abdominal segment allows distinguishing whether an androchrome or an infuscans phenotype will develop (Sánchez-Guillén et al. 2005). A proportion of females $(25 \%)$ that become androchrome when mature do not go through the violacea stage and shows lightgreen coloration when immature (Fig. 1; Sánchez-Guillén et al. 2005). Here, we limit comparison to only two immature morphs, rufescens and violacea, as these are the more common immature female types.

\section{Morph Frequency and Mating Success}

Sampling occurred at 26 populations across The Netherlands and Belgium between June and August 2007 (see Hammers and Van Gossum 2008 where we deal in detail with differences in mating success between mature female morphs). All sites included were $>5 \mathrm{~km}$ apart and were not part of the same water body. I. elegans is reproductively active from 08:00 until 16:00, however the peak of mating activity is between the hours of 10 to 15 (Cordero Rivera and Sánchez-Guillén 2007) and with most animals not yet engaged in reproductive activity before 10:00. For estimating population frequency of immature, mature and each separate female morph we collected damselflies by sweeping an insect net through shoreline vegetation (within $10 \mathrm{~m}$ from the shoreline, where most mating occurs) during early morning hours (0830 to 1000 hours; this same methodology was applied by Cordero Rivera and 
Sánchez-Guillén 2007; Hammers and Van Gossum 2008). For this, we transcribed ' $\infty$-shaped' figures with an insect net while walking slowly. At each site, we made several sets of sweeps but collected damselflies only once at each area within a site. We aimed at collecting minimally 50 females at each location (mean \pm SE: $86.5 \pm 5$.6; range 42 to 148). Therefore, the number of sweeps made at a site ranged from five to ten depending on when the minimal number of 50 was reached. Sex and morph of all individuals netted were recorded, and to preclude multiple counts, we marked all individuals prior to release with a dot on one of the wings, using a permanent marker. If females were caught more than once (which occurred seldom because we sampled each area within a site only once) they were not included again, nor marked again, but simply released.

Female morph mating frequencies were estimated during the daily period of reproductive activity (1000 to 1500 hours) by collecting pairs in copula within a distance of $10 \mathrm{~m}$ from the water (see Cordero Rivera and Sánchez-Guillén 2007). Prior to release, we marked females caught in copula with a black stripe on one of the wings, using a permanent marker. We first located copulating pairs, which were always highly visible, and only then identified female morph. We aimed at observing a minimum of 30 copulating pairs at each site (mean $\pm \mathrm{SE}$ : 47.0 \pm 4.7 ; range 19 to 131). To avoid a potential sampling or observer bias, we randomly sampled all vegetation types present at the water's edge for each population and all sampling was conducted by the same person $(\mathrm{MH})$.

\section{Male Mate Preference}

Male preferences for the two immature types were scored using one-female presentation experiments (for methodology see also Forbes et al. 1997; Van Gossum et al. 2007). The experiment was performed at two different populations in The

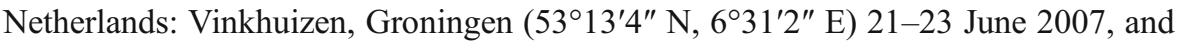
Zanderij Craillo, Hilversum (52 $15^{\prime} 21^{\prime \prime} \mathrm{N}, 5^{\circ} 09^{\prime} 56^{\prime \prime}$ E) 7-9 July 2007. These populations were selected because of the large numbers of I. elegans present and because of contrasting immature female morph frequencies (see "Results" section). Females of both immature color morphs were captured and glued by their legs and head capsule to the bottom of a grass stem at a $30^{\circ}$ angle. Such restrained females could not resist mating attempts, and thereby allowed us to specifically evaluate male interest for the two female types. For each presentation, a perching male was located in the vegetation. We introduced the female model just lateral to a perched male (i.e. less than three cm away) with the grass stem held vertically. Presentations were stopped if a male showed a reaction (time was monitored with a stopwatch), or after $120 \mathrm{~s}$ if the male remained perched. After a focal male's response was observed, it was captured and marked with a permanent marker to prevent testing the same male again. Each female specimen was presented sequentially to three perching males.

Male reactions were categorized as follows: attempting to grasp the female at the pronotum with his claspers (attempting tandem formation) or not. If a male attempted tandem formation, we further noted whether the tandem position was successfully achieved or not. Attempting tandem formation is a clear sign of mating interest by the male (e.g. Corbet 1999). Alternative behaviors were grouped as nonsexual and ranged from no obvious reaction to flying at and touching the female specimen without showing any attempt to clasp the model in tandem. 


\section{Statistical Analyses}

To investigate how and to what extent mating success differed between female morphs, we compared observed and expected frequencies (calculated from the estimated population frequencies) of immature and mature female morphs in copula, using Chi-square tests. In addition, because mating frequencies of immature females were low (see Results); we were not able to statistically test whether the mating frequencies of the two immature female morphs differed within populations. Therefore, we explored this question in three ways. First, we compared mating frequencies of violocea and rufescens with a Chi-squared test by combining all data of all populations and assuming independence of observations. Second, we pooled populations that showed comparable proportions of immature females. To achieve this, we selected four different groups from the dataset, based on the population frequencies of a morph: proportion of rufescens out of immature females of 0.3-0.4; $0.4-0.5 ; 0.5-0.6$ and $0.6-0.7$ (see Table 2), and performed Chi-squared test for each group. Third, we plotted proportions of rufescens and violacea in the immature population versus their proportions among mating immature females and compared observed versus expected frequencies with a binomial test. To investigate whether patterns of mating frequency in immature female morphs are similar to patterns in mature female mating frequency, we performed a GLM. The GLM consisted of mature female morph mating frequency as the dependent variable, and female morph and population morph frequency as the covariates. Mature female mating frequencies were arcsin transformed prior to fitting the GLM to meet parametric assumptions.

For analyses on male mate preference for both immature female morphs, we scored the number of times a given female specimen evoked an attempted male tandem response (minimum 0 out of three males, maximum three out of three males). We then compared the number of male tandem responses out of the three trials the two immature female morphs evoked using Mann-Whitney $U$ tests. We thereby removed a potential lack of independence in our data (the model specimen was the replicate, not the male's approach in each trial). We give two-tailed $P$-values while all analyses were performed using SPSS 16.0 (SPSS Inc., Chicago, IL, U.S.A.).

\section{Results}

Population Morph Frequencies and Mating Frequencies

Proportions of immature females to the total number of females across populations ranged from 0.21 to $0.75(0.55 \pm 0.03 \mathrm{SE})$. Populations were sampled on different dates but this did not explain the variation in proportions of immature females (Spearman rank correlation: $r_{s}=-0.065, p=0.751$ ). Mating frequencies of immature females, however, were much lower than predicted from their population frequency, and this was consistent across all populations (overall $\chi_{25}^{2}=1268.64, p<0.001$; Table 1 for $\chi^{2}$ tests per population). Moreover, mating frequencies of immature females were lower than mating frequencies of mature females across all populations (Wilcoxon matched pairs: $z=-4.458, n=26, p<0.001$ ). There was no relation 
between the proportion of immature females in the population and the mating frequency of immature females (Spearman rank correlation: $r_{s}=0.324, p=0.106$ ).

Combining all data of all populations and assuming independence of observations, the two immature female morphs differed in mating frequency. Rufescens was found mating more frequently per capita than violacea $\left(\chi_{1}^{2}=7.61, p=0.006\right)$. Over the four artificially selected groups consisting of populations with comparable immature female population morph frequencies (see "Materials and Methods" and Table 2), rufescens had a greater probability of being found mating compared to violacea $\left(\chi_{3}^{2}=12.76, p=0.005\right)$. For the group where rufescens was the minority

Table 1 Frequencies of Immature and Mature Females Ischnura elegans and Observed Mating Frequencies for Different Populations in The Netherlands and Belgium

\begin{tabular}{|c|c|c|c|c|c|c|c|c|}
\hline \multirow[t]{2}{*}{ Population } & \multirow[t]{2}{*}{ Nfem } & \multicolumn{2}{|c|}{ Proportion in population } & \multirow[t]{2}{*}{ Ncop } & \multicolumn{2}{|c|}{ Proportion in mating pairs } & \multirow[t]{2}{*}{$\chi^{2}$} & \multirow[t]{2}{*}{$P$ value } \\
\hline & & Immature $q$ & Adult $q$ & & Immature + & Adult $q$ & & \\
\hline Slingeland & 88 & 0.50 & 0.50 & 33 & 0.12 & 0.88 & 18.94 & $<0.001$ \\
\hline Walenhoek & 89 & 0.63 & 0.37 & 47 & 0.04 & 0.96 & 69.33 & $<0.001$ \\
\hline Vinkhuizen & 111 & 0.72 & 0.28 & 59 & 0.07 & 0.93 & 124.96 & $<0.001$ \\
\hline Winschoten & 59 & 0.46 & 0.54 & 31 & 0.06 & 0.94 & 19.30 & $<0.001$ \\
\hline Haren & 68 & 0.54 & 0.46 & 30 & 0.17 & 0.83 & 17.23 & $<0.001$ \\
\hline Kommerzijl & 64 & 0.50 & 0.50 & 34 & 0.06 & 0.94 & 26.47 & $<0.001$ \\
\hline Ballastplaatbos & 148 & 0.72 & 0.28 & 71 & 0.21 & 0.79 & 89.07 & $<0.001$ \\
\hline Maasvlakte & 77 & 0.61 & 0.39 & 71 & 0.06 & 0.94 & 91.65 & $<0.001$ \\
\hline Best & 47 & 0.34 & 0.66 & 30 & 0.10 & 0.90 & 7.72 & 0.005 \\
\hline Hardinxveld & 114 & 0.71 & 0.29 & 60 & 0.07 & 0.93 & 120.93 & $<0.001$ \\
\hline Utrecht & 131 & 0.75 & 0.25 & 37 & 0.08 & 0.92 & 87.35 & $<0.001$ \\
\hline Holten & 73 & 0.49 & 0.51 & 131 & 0.02 & 0.98 & 119.69 & $<0.001$ \\
\hline Valkenswaard & 64 & 0.42 & 0.58 & 53 & 0.06 & 0.94 & 28.99 & $<0.001$ \\
\hline Maltha & 42 & 0.21 & 0.79 & 31 & 0.03 & 0.97 & 6.10 & 0.014 \\
\hline Zouweboezem & 82 & 0.48 & 0.52 & 61 & 0.15 & 0.85 & 26.32 & $<0.001$ \\
\hline Raalte & 72 & 0.57 & 0.43 & 33 & 0.21 & 0.79 & 17.19 & $<0.001$ \\
\hline Oostwold & 65 & 0.46 & 0.54 & 32 & 0.03 & 0.97 & 23.84 & $<0.001$ \\
\hline Zanderij Craillo & 135 & 0.49 & 0.51 & 47 & 0.15 & 0.85 & 21.74 & $<0.001$ \\
\hline Annabos & 106 & 0.72 & 0.28 & 39 & 0.08 & 0.92 & 78.74 & $<0.001$ \\
\hline Effen & 52 & 0.42 & 0.58 & 19 & 0.05 & 0.95 & 10.68 & 0.001 \\
\hline Werkendam & 98 & 0.46 & 0.54 & 38 & 0.29 & 0.71 & 4.41 & 0.036 \\
\hline Woudenberg & 125 & 0.62 & 0.38 & 38 & 0.16 & 0.84 & 35.19 & $<0.001$ \\
\hline Houten & 85 & 0.60 & 0.40 & 41 & 0.07 & 0.93 & 47.41 & $<0.001$ \\
\hline Goes & 57 & 0.44 & 0.56 & 31 & 0.03 & 0.97 & 20.79 & $<0.001$ \\
\hline Koudekerke & 92 & 0.64 & 0.36 & 93 & 0.09 & 0.91 & 124.66 & $<0.001$ \\
\hline Kerkelanden & 106 & 0.72 & 0.28 & 32 & 0.28 & 0.72 & 29.94 & $<\backslash 0.001$ \\
\hline
\end{tabular}

The frequency of immature and mature females in mating pairs is compared with the expected frequency based on the population frequency

Nfem total number of females caught at each population, Ncop total number of females mating 
Table 2 Frequencies of Violacea and Rufescens Females of Ischnura elegans and Their Respective Mating Frequencies

\begin{tabular}{|c|c|c|c|c|c|c|c|c|c|}
\hline \multirow[t]{2}{*}{ Group } & \multirow[t]{2}{*}{ Nim } & \multirow[t]{2}{*}{ Npop } & \multicolumn{2}{|c|}{ Frequency pop } & \multicolumn{2}{|c|}{ Mating frequency } & \multirow[t]{2}{*}{ Vio } & \multirow[t]{2}{*}{$\chi^{2}$} & \multirow[t]{2}{*}{$P$ value } \\
\hline & & & Ruf & Vio & Ncop & Ruf & & & \\
\hline 1 & 314 & 6 & 0.35 & 0.65 & 36 & 0.50 & 0.50 & 3.56 & 0.059 \\
\hline 2 & 389 & 7 & 0.45 & 0.55 & 21 & 0.67 & 0.33 & 3.98 & 0.046 \\
\hline 3 & 427 & 9 & 0.55 & 0.45 & 70 & 0.69 & 0.31 & 5.21 & 0.022 \\
\hline 4 & 149 & 3 & 0.65 & 0.35 & 14 & 0.64 & 0.36 & 0.00 & 0.955 \\
\hline
\end{tabular}

Four different groups were selected from the dataset based on the proportion of rufescens out of immature females: group $1(0.3-0.4)$; group $2(0.4-0.5)$; group $3(0.5-0.6)$ and group $4(0.6-0.7)$. Thus, groups present pools of populations that show comparable rufescens morph proportions (see also "Results"). Frequencies of both immature morphs are compared with the expected frequency based on group class proportions

Nim total number of immature females, Npop number of populations in group, ruf rufescens, vio violacea, Ncop total number of immature females mating

immature morph (0.3-0.4), this morph tended to mate slightly more than expected based on frequency (Table 2). For the groups where the immature morphs occurred at close to equal proportions $(0.4-0.5$ and $0.5-0.6)$, rufescens was found mating more often than expected. Only in the populations where rufescens was the majority morph, was there no observed difference between expected and observed mating frequency. When comparing proportions of rufescens and violacea in the immature population versus their proportions among mating immature females (Fig. 2a), rufescens appears to mate more frequently than would be expected based on their frequency among immature females. Because of low mating frequencies several 1 and 0 data result, but it is interesting to note that rufescens shows many more 1 and violacea many more 0 .

Together, rufescens was seen more often mated than violacea. We then asked whether this pattern as seen for immature females was repeated for mature females. To this end we compared androchrome and infuscans ("mature" violacea) with rufescens-obsoleta ("mature" rufescens) for mating frequencies. Consistent with our observations for immatures, when controlling for population frequency, mature female morphs differed in mating frequencies (Fig. 2b; GLM: $F_{2,74}=54.61, p<$ 0.001). Rufescens-obsoleta is observed more mating compared to androchrome $\left(F_{1,74}=104.34, p<0.001\right)$ and infuscans females $\left(F_{1,74}=18.86, p<0.001\right.$; see also Hammers and Van Gossum 2008). Rufescens-obsoleta is observed more often mating compared to both infuscans and rufescens females (Fig 2b).

\section{Male Mate Preference}

For each of two populations (Vinkhuizen and Zanderij Craillo), male response was quantified for 20 rufescens and 20 violacea females. These populations differed in immature morph frequencies. The proportion of rufescens females at Vinkhuizen was $57 \%$, where as at Zanderij Craillo this proportion was $36 \%$. Combining the data 
Fig. 2 Frequencies of a immature female morphs as proportion of total number of immature females and b mature female morphs as proportion of total number of mature females and their observed mating frequencies. Rufescens-obsoleta is the mature morph of rufescens and androchrome and infuscans are the mature morphs of violacea. The diagonal represents mating frequencies that would be expected when females are mating according to their population frequencies. In both rufescens and mature rufescens, most data points are above the line, indicating a higher mating frequency than would be predicted from population frequencies.

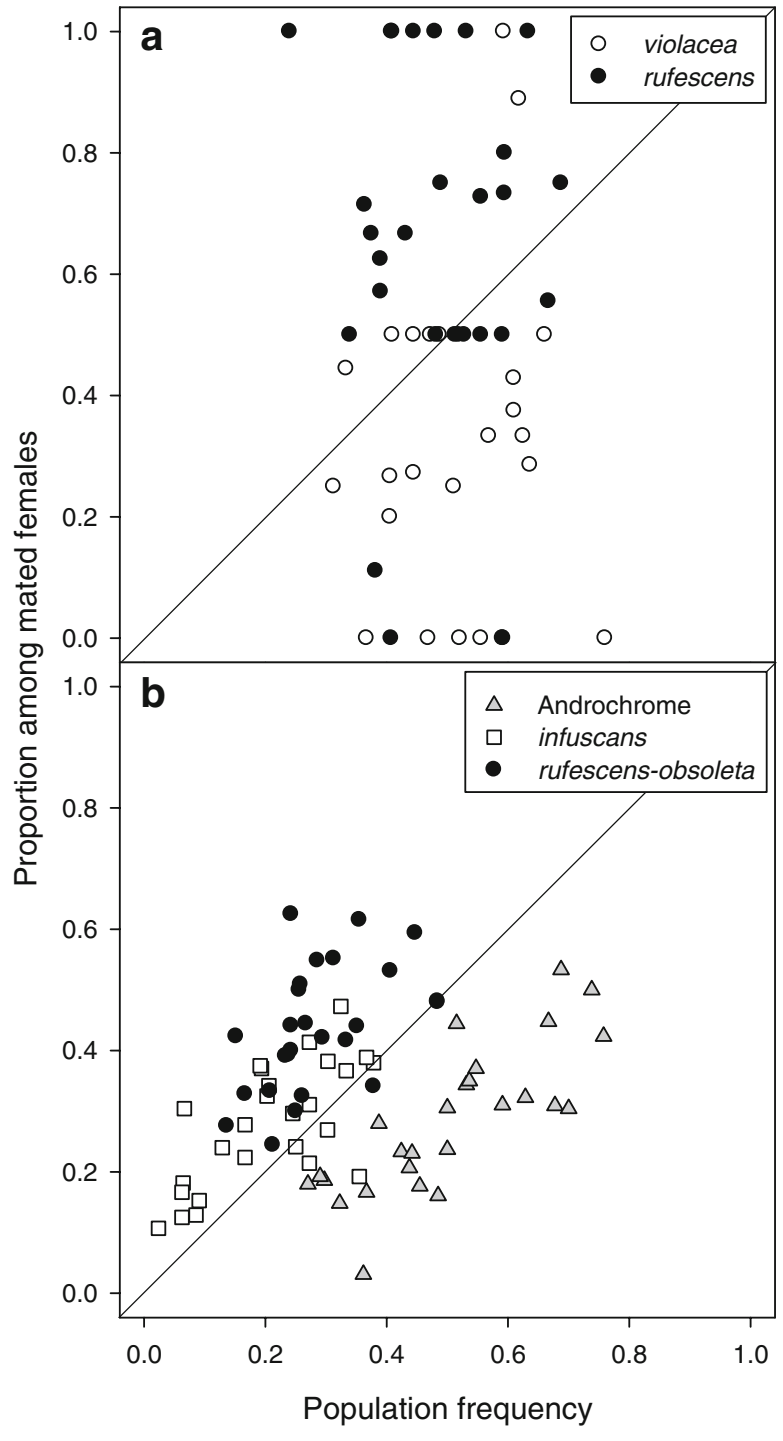

of both populations, males did not differ in sexual interest for violacea or rufescens (Mann-Whitney: $U=736.5, p=0.525$. Also within populations, males did not differ in sexual interest for violacea or rufescens (Fig. 3; Vinkhuizen, Mann-Whitney: $U=$ 149, $p=0.144$; Zanderij Craillo, Mann-Whitney: $U=188, p=0.736$. However, the number of male tandem attempts differed between populations, with a higher number of tandem attempts at Vinkhuizen compared to Zanderij Craillo (Fig. 3; Mann-Whitney: $U=584.5, p=0.031)$. Rufescens attracted more male interest at Vinkhuizen than violacea (Mann-Whitney: $U=111, p=0.012$ ), while at Zanderij Craillo rufescens tended to attract less male interest than violacea (Mann-Whitney: $U=135.5, p=0.066$ ). Repeating these analyses with successful tandem formations gave similar results. Further, the latency time of males (from the start of the trial until 
Fig. 3 Male Ischnura elegans mating (i.e. tandem) attempts (averages and SE) on rufescens and violacea immature females for two populations with different immature morph frequencies.

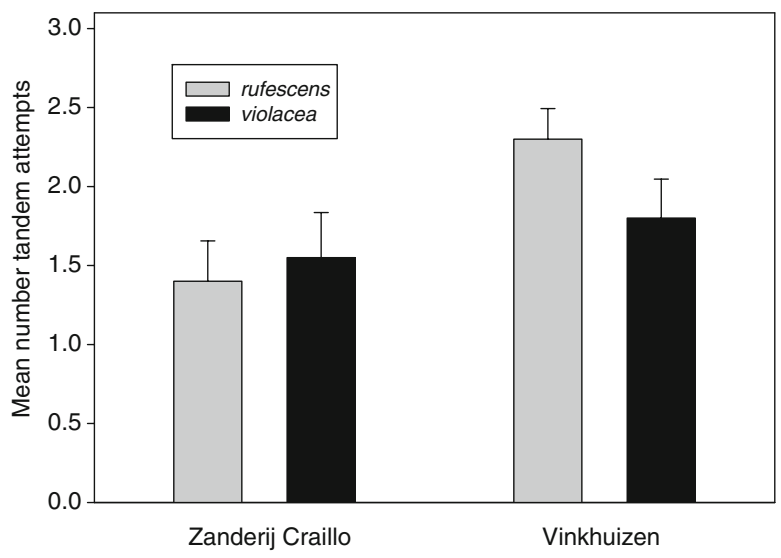

the male showed a sexual response) did not differ when confronted with either a violacea or rufescens female at either site (Vinkhuizen, Mann-Whitney: $U=703, p=$ 0.241; Zanderij Craillo, Mann-Whitney: $U=431.5, p=0.970)$.

\section{Discussion}

We show mating success of female morphs to differ among morphs and across populations. Specifically, immature females mate at a much lower frequency than would be expected from their population frequencies and this was consistent across study populations. Between immature female morphs, rufescens is found more often mating in the wild compared to violacea, a pattern that is repeated when comparing rufescens-obsoleta ("mature" rufescens) with androchrome and infuscans ("mature" violacea) females. If immature females mate and differ in mating frequency, as shown here, then mating frequencies of mature female morphs may be affected. Posed differently, mature androchrome and gynochrome mating frequencies may not only depend on morph frequencies and female behavior, but also less directly on how often immature female morphs mate (see also Sirot et al. 2003). Experimental female presentation trials indicated that males did not prefer either immature female color morph, but male eagerness to mate differed between populations.

It is not surprising that immature females show reduced mating success compared to mature females: I. elegans shows male scramble mate choice, copulations last several hours (Krieger and Krieger-Loibl 1958; Miller 1987) and reproductive lifespan is limited to a few weeks (Parr and Parr 1972; Van Noordwijk 1978). Malemale competition for access to females will be intense and not all males will be successful in achieving copulations during their lifetimes (Cordero et al. 1997). Despite this impetus on males to mate, approaching immature females for mating may render little immediate fitness benefits, considering that these females may not have mature eggs yet and that last sperm precedence will reduce the likelihoods of fertilization when females mate multiply (Cooper et al. 1996). For males, it thus may be beneficial not to spend time and energy mating immature females, but invest in locating and attempt to mate mature females. To this end, differences in body 
coloration between mature and immature females may facilitate discrimination by males. In support, such age-dependent color differences only occur in the genus Ischnura (see Fincke et al. 2005), and it is also only in this genus that immature and mature females coexist at the mating site (Parr 1973; Fincke 1987; Hinnekint 1987). From a female's perspective, immature females may reject male mating attempts until they carry a clutch of mature eggs (Banham 1990; Fincke 1997). Conversely, given that sperm can survive for several days in the female storage organs and that a single insemination may suffice for fertilizing the lifetime number of eggs (Fincke 1987; Cordero 1989), mating while immature may provide benefits to females that can start laying fertile eggs immediately when mature. In addition, although females have to decide on whether or not to copulate (Fincke et al. 1997), costs of rejecting a persistent male may be higher than accepting to copulate (Rowe 1992, Cordero and Andrés 2002). Obviously, since males and immature females have conflicting mating interests, future research should focus on determining whether low mating success of immature females is due to male or female behavior, or both. In addition, immature female that were observed mating may still show immature coloration but already have mature eggs, i.e. the change in body color is about to occur. Males may then use abdomen width rather then body coloration in deciding whether to mate a female. Perhaps this may also explain why rufescens and violacea differ in mating rates. For example, the rufescens immature color phase may last enough for these females to mature eggs, while this is not the case for violacea, which on average is less mature in age. Therefore, future workers may need to dissect immature females that are found in copula and evaluate whether these have already mature eggs.

Some further insights may be gained based on results of male preference experiments. We note that male preference experiments involve the female being constrained and therefore unable to exhibit mating rejection behavior. While violacea immature females of I. elegans were found less often in copula at a natural site compared to androchrome and infuscans females, violacea females elicited a higher male response in one-female presentation experiments when compared to one infuscans, but not to androchromes (Gorb, 1999). Rufescens and rufescens-obsoleta morphs were not included in this study because of absence of these morphs in the study area (Gorb, 1999). Also, using one-female presentation experiments Cordero (1989) observed higher male response to immature than mature females, but fewer immature compared to mature females effectively ended in tandem or copula. Further, in our mate preference experiments with immature females, male response occurred in about half of the trials (Fig. 3), clearly more than would be expected given our results on mating frequencies of immature females in natural populations. Performing two-female presentation experiments, offering males I. elegans the choice for an immature and mature female simultaneously, immature females were approached for mating in less than $20 \%$ of the trials (Van Gossum et al. 2001c). Indeed, also when comparing between immature females, observations of immature females mating are not consistent with results from mate preference experiments, indicating that female behavior may be more relevant than body coloration or abdomen width for predicting female morph mating success (see also Cordero et al. 1998; Van Gossum et al. 2005). While in presentation trials males do not show preference for either immature morph, mating success of rufescens appears higher than that of violacea across natural populations and immature morph frequencies. 
Possibly, these two immature female morphs differ in their ability to reject male mating attempts, similarly as has been suggested for mature females (Forbes et al. 1997; Van Gossum et al. 2001a; Sirot et al. 2003). Together, it may be argued that male mate preference experiments cannot fully explain differences in mating success between immature and mature females, or between rufescens and violacea immature females in the field.

Within immature females, rufescens is observed mated more often compared to violacea, a pattern that appears similar for mature females. Perhaps the immature and mature version of a morph show comparable male avoidance behavior, despite ontogenetic changes in body coloration. Given that excessive male sexual attention may negatively affect female reproductive success (e.g. Sirot and Brockman 2001), our results may indicate that rufescens suffers costs both when mature and immature at a range of female morph frequencies. Detailed studies on the behavior of each female morph are needed to determine the pattern of mating success between mature and immature females. Past studies on female morph behavior have pooled the two mature gynochrome females together (e.g. Van Gossum et al. 2001a), however, we suggest future studies should evaluate the behavior of the two morphs separately. Finally, studies evaluating male mate preference should consider the impact of the distractions males face when searching for a female such as the frequency of mature females, immature females, and both males and females of similar species in a habitat.

Acknowledgements We are grateful to Adolfo Cordero Rivera, Arne Iserbyt, Jessica Bots, Tom Sherratt, and three anonymous referees for useful and constructive comments on the manuscript. HVG is a postdoctoral fellow with the Fund for Scientific Research-Flanders and benefited for this research from a grant from the University of Antwerp. RASG was supported by a fellowship from the Spanish Ministry of Education and Science (Plan de Formación del Personal Investigador).

Open Access This article is distributed under the terms of the Creative Commons Attribution Noncommercial License which permits any noncommercial use, distribution, and reproduction in any medium, provided the original author(s) and source are credited.

\section{References}

Armett-Kibel C, Meinertzhagen IA (1983) Structural organization of the ommatidium in the ventral compound eye of the dragonfly Sympetrum. J Comp Physiol 151:285-294

Arnqvist G, Nilsson T (2000) The evolution of polyandry: Multiple mating and female fitness in insects. Anim Behav 60:145-164

Askew RR (2004) The dragonflies of Europe. Harley Books, Colchester, p 308

Banham WMT (1990) Non-random mating in the polymorphic damselfly Ischnura elegans. Ph.D. thesis, University of Manchester, 250pp

Briscoe AD, Chittka L (2001) The evolution of color vision in insects. Annu Rev Entomol 46:471-510

Clutton-Brock TH, Price OF, MacColl ADC (1992) Mate retention, harassment, and the evolution of ungulate leks. Behav Ecol 3:234-242

Cook SE, Vernon JG, Bateson M, Guilford T (1994) Mate choice in the polymorphic African swallowtail butterfly, Papilio dardanus: Male-like females may avoid sexual harassment. Anim Behav 47:389-397

Cooper G, Miller PL, Holland PW (1996) Molecular genetic analysis of sperm competition in the damselfly Ischnura elegans (Vander Linden). Proc R Soc Lond B Biol Sci 263:1343-1349

Corbet PS (1999) Dragonflies: Behavior and Ecology of Odonata. Harley Books, Colchester, p 829

Cordero A (1989) Reproductive behaviour of Ischnura graellsii (Rambur) (Zygoptera: Coenagrionidae). Odonatologica 18:237-244 
Cordero A, Andrés JA (2002) Male coercion and convenience polyandry in a calopterygid damselfly. J Insect Sci 2:14 Available online: insectscience.org/2.14

Cordero Rivera A, Sánchez-Guillén RA (2007) Male-like females of a damselfly are not preferred by males even if they are the majority morph. Anim Behav 74:247-252

Cordero A, Santolamazza S, Utzeri C (1997) Male mating success in a natural population of Ischnura elegans (Vander Linden) (Odonata: Coenagrionidae). Odonatologica 26:459-465

Cordero A, Santolamazza S, Utzeri C (1998) Mating opportunities and mating costs are reduced in androchrome female damselflies, Ischnura elegans (Odonata). Anim Behav 55:185-197

Crudgington HS, Siva-Jothy MT (2000) Genital damage, kicking and early death. Nature, 407:855-856

Fincke OM (1987) Female monogamy in the damselfly Ischnura verticalis Say (Zygoptera: Coenagrionidae). Odonatologica 16:129-143

Fincke OM (1997) Conflict resolution in the Odonata: Implications for understanding female mating patterns and female choice. Biol J Linn Soc 60:201-220

Fincke OM (2004) Polymorphic signals of harassed female odonates and the males that learn them support a novel frequency-dependent model. Anim Behav 67:833-845

Fincke OM, Waage JK, Koenig WD (1997) Natural and sexual selection components of odonate mating patterns. In: Choe JC, Crespi BJ (eds) The Evolution of Mating Systems in Insects and Arachnids. Cambridge University Press, Cambridge, pp 58-74

Fincke OM, Jödicke R, Paulson DR, Schultz J (2005) The evolution and frequency of female color morphs in Holarctic Odonata: why are male-like females typically the minority. Int J Odonatol $8: 183-212$

Forbes MR, Schalk G, Miller JG, Richardson JML (1997) Male-female morph interactions in the damselfly Nehalennia irene (Hagen). Can J Zool 75:253-260

Galeotti P, Rubolini D, Dunn PO, Fasola M (2003) Colour polymorphism in birds: causes and functions. J Evol Biol 16:635-646

Gorb SN (1999) Visual cues in mate recognition in the damselfly Ischnura elegans Vander Linden (Zygoptera: Coenagrionidae). Int J Odonatol 2:83-93

Gosden TP, Svensson EI (2007) Female sexual polymorphism and fecundity consequences of male mating harassment in the wild. PLoS ONE 2:e580

Gray SM, McKinnon JS (2007) Linking color polymorphism maintenance and speciation. Trends Ecol Evol 22:71-79

Gross MR (1996) Alternative reproductive strategies and tactics: Diversity within sexes. Trends Ecol Evol 11:92-98

Hammers M, Van Gossum H (2008) Variation in female morph frequencies and mating frequencies, random, frequency-dependent harassment or male-mimicry? Anim Behav 76:1403-1410

Hinnekint BON (1987) Population dynamics of Ischnura elegans (Vander Linden) (Insecta: Odonata) with special reference to morphological colour changes, female polymorphism, multiannual cycles and their influence on behaviour. Hydrobiologia 146:3-31

Krieger F, Krieger-Loibl E (1958) Beitrage zum Verhalten von Ischnura elegans und Ischnura pumilio (Odonata). Z Tierpsychol 15:82-93

Krupa JJ, Leopold WR, Sih A (1990) Avoidance of male giant water striders by females. Behaviour $115: 247-253$

Miller PL (1987) Dragonflies. Cambridge University Press, New York, p 118

Miller MN, Fincke OM (1999) Cues for Mate Recognition and the Effect of Prior Experience on Mate Recognition in Enallagma Damselflies. J Insect Behav 12:801-814

Murdoch WW (1969) Switching in general predators: Experiments on predator specificity and stability of prey populations. Ecol Monogr 39:335-354

Nielsen MG, Watt WB (2000) Interference competition and sexual selection promote polymorphism in Colias (Lepidoptera, Pieridae). Funct Ecol 14:718-730

Parr MJ (1973) Ecological studies of Ischnura elegans (Vander Linden) (Zygoptera: Coenagrionidae). Survivorship, local movements and dispersal. Odonatologica 2:159-174

Parr MJ, Parr M (1972) Survival rates, population density and predation in the damselfly, Ischnura elegans (Vander Linden)(Zygoptera: Coenagrionidae). Odonatologica 1:137-141

Robertson HM (1985) Female dimorphism and mating behaviour in a damselfly, Ischnura ramburi: Females mimicking males. Anim Behav 33:805-809

Rowe L (1992) Convenience polyandry in a water strider: Foraging conflicts and female control of copulation frequency and guarding duration. Anim Behav 44:189-202

Rowe L, Arnqvist G, Sih A, Krupa JJ (1994) Sexual conflict and the evolutionary ecology of mating patterns: Water striders as a model system. Trends Ecol Evol 9:289-293 
Sánchez-Guillén RA, Van Gossum H, Cordero Rivera A (2005) Hybridization and the inheritance of female colour polymorphism in two ischnurid damselflies (Odonata: Coenagrionidae). Biol J Linn Soc $85: 47-481$

Sherratt TN (2001) The evolution of female-limited polymorphisms in damselflies: A signal detection model. Ecol Lett 4:22-29

Sirot LK, Brockmann HJ (2001) Costs of sexual interactions to females in Ramburs forktail damselfly, Ischnura ramburi (Zygoptera: Coenagrionidae). Anim Behav 61:415-424

Sirot LK, Brockmann HJ, Marnis C, Muschett G (2003) Maintenance of a female-limited polymorphism in Ischnura ramburi (Zygoptera: Coenagrionidae). Anim Behav 66:763-775

Turner GF, Seehausen O, Knight ME, Allender CJ, Robinson RL (2001) How many species of cichlid fishes are there in African lakes? Mol Ecol 10:793-806

Van Gossum H, Stoks R, Matthysen E, Valck F, De Bruyn L (1999) Male choice for female colour morphs in Ischnura elegans (Odonata, Coenagrionidae): testing the hypotheses. Anim Behav 57:1229-1232

Van Gossum H, Stoks R, De Bruyn L (2001a) Frequency-dependent male mate harassment and intraspecific variation in its avoidance by females of the damselfly Ischnura elegans. Behav Ecol Sociobiol 51:69-75

Van Gossum H, Stoks R, De Bruyn L (2001b) Reversible frequency-dependent switches in male mate choice. Proc R Soc Lond B Biol Sci 268:83-85

Van Gossum H, Stoks R, De Bruyn L (2001c) Discriminative mate choice in relation with female maturation in Ischnura elegans (Odonata: Coenagrionidae). Int J Odonatol 4:83-91

Van Gossum H, Stoks R, De Bruyn L (2005) Lifetime fitness components in female colour morphs of a damselfly: density- or frequency-dependent selection? Biol J Linn Soc 86:515-523

Van Gossum H, Beirinckx K, Forbes MR, Sherratt TN (2007) Reproductive interference between Nehalennia damselfly species. Ecoscience 14:1-7

Van Noordwijk M (1978) A mark-recapture study of coexisting zygopteran populations. Odonatologica 7:353-374

Vercken E, Massot M, Sinervo B, Clobert J (2007) Colour variation and alternative reproductive strategies in females of the common lizard Lacerta vivipara. J Evol Biol 20:221-232 